\title{
Effect of thermal insulation on hygric and thermal conditions in the envelopes of renovated historical buildings
}

\author{
J. Maděra, V. Kočí \& R. Černý \\ Department of Materials Engineering and Chemistry, Faculty of Civil \\ Engineering, Czech Technical University in Prague, Czech Republic
}

\begin{abstract}
The effects of selected exterior thermal insulation systems on hygric and thermal conditions in the envelopes of renovated historical buildings are studied. The load bearing structures formed by typical stone materials used on Czech territory, such as sandstone and argillite, and provided with different types of insulation systems are subjected to computational hygrothermal analysis. The coupled heat and moisture transport problem is solved using the standard Galerkin finite element approach, and a computational implementation is performed. The computer code in $\mathrm{C}++$ is then used in a series of computational simulations. Climatic data corresponding to the test reference year for Prague are used as boundary conditions. The results of computer simulations of moisture and temperature fields are then utilized in the subsequent service life analysis. Keywords: hygrothermal simulation, external insulation, heat and moisture transport, finite element method.
\end{abstract}

\section{Introduction}

For thermal insulation of existing and newly built structures, exterior thermal insulation systems are the most frequently applied. They are capable of formation of compact insulation layers; herewith the possible thermal bridges that can lead in specific cases to a significant increase of thermal losses are easily eliminated. Application of exterior thermal insulation systems also reduces the thermal loading of envelope structures (especially of their joints) that are usually exposed to the negative effects of temperature changes. The exterior insulation can be realized in the form of a contact system or with air gap. The contact 
insulation systems form a compact structure. The thermal insulation also plays here the bearing role for surface layers. The facade surfaces are made mostly of plaster and sometimes of glued facings. In the case of systems with an air gap the thermal insulation layer is fixed between the parts of the bearing grid that supports the facade elements. These can be formed by glass, metal, wood, cement composites, ceramic materials, etc.

The presence of thermal insulation significantly affects not only the thermal but also hygric performance of the building envelope, so the proper choice must be made wisely. One of the possibilities in how to choose correctly is to use the results of computational simulation of coupled heat and moisture transport, which give us a relatively precise image about the behaviour of a building envelope. An example of usage of this method is described further in this paper.

\section{Computational analysis}

The computational analysis was accomplished by computer code HEMOT [1-2], which was developed at the Department of Material Engineering and Chemistry, Faculty of Civil Engineering, Czech Technical University in Prague on the basis of the general finite element package SIFEL [3]. As basic input parameters of the mathematical model, material parameters of used materials, scheme of construction detail, initial and boundary conditions and time specification of simulation were required. A description in more detail of all input parameters is given later.

In the computer simulations we focused on a comparison of hygrothermal behavior of several building envelopes based on natural stones provided with three different types of thermal insulation.

\subsection{Mathematical model}

Künzel's mathematical model of heat and moisture transport [4] was used in the simulations which can be formulated as

$$
\begin{aligned}
& \frac{d \rho_{v}}{d \varphi} \frac{\partial \varphi}{\partial t}=\operatorname{div}\left[D_{\varphi} \operatorname{grad} \varphi+\delta_{p} \operatorname{grad}\left(\varphi p_{s}\right)\right] \\
& \frac{d H}{d T} \frac{\partial T}{\partial t}=\operatorname{div}(\lambda \operatorname{grad} T)+L_{v} \operatorname{div}\left[\delta_{p} \operatorname{grad}\left(\varphi p_{s}\right)\right]
\end{aligned}
$$

where $\rho_{v}$ is the partial density of moisture, $\varphi$ relative humidity, $\delta_{p}$ permeability of water vapour, $p_{s}$ partial pressure of saturated water vapour, $H$ enthalpy density, $L_{v}$ heat of evaporation, $\lambda$ thermal conductivity and $T$ temperature,

$$
D_{\varphi}=D_{w} \frac{d \rho_{v}}{d \varphi}
$$

is liquid moisture diffusivity coefficient, $D_{w}$ capillary transport coefficient. 


\subsection{Scheme of construction detail}

Six variations of building envelope based on natural stones were chosen for simulation, in order to analyze the consequences of different material combinations. We assumed two types of load bearing materials (sandstone and argillite) in thickness of $600 \mathrm{~mm}$ provided with three different types of thermal insulations (expanded polystyrene, hydrophobic and hydrophilic mineral wool) $120 \mathrm{~mm}$ thick. Thermal insulation is connected to the wall using an adhesive layer made from Mamut M2 mortar in a thickness of $10 \mathrm{~mm}$. The whole building envelope is provided from the interior and exterior side with lime-pozzolana render (10 mm thick).

\subsection{Material parameters}

One type of sandstone coming from quarry Božanov in the Czech Republic is analyzed together with one type of argillite coming from quarry Džbán. Many historical buildings in the Czech Republic were built using several kinds of sandstone. Siliceous raw-grained sandstone was usually used for historical architectural constructions (walls, portals, window frames) for its strength. Ornamental parts of the architecture (gothic flowers, romantic shells) and sculptures (from the Romanesque period up to now) were made of fine-grained calcite-argillaceous sandstone. Studied sandstone was formed by suboval quartz clasts, tourmaline, epidote, muscovite and zircone. Also argillite was very popular material in historical architecture. It was used for sacral as well as for secular buildings, flagstone pavements, roof slabs, and facing. The studied argillite constituents are illite, calcite, minerals on the basis of $\mathrm{SiO}_{2}$ having granularity $0.3-0.15 \mathrm{~mm}$, feldspar, and mica, whereas rigid materials form 40 $60 \%$ of argillite volume. The envelope is provided from the interior and exterior side with lime-pozzolana render, which is one of the most favorite of conservationists [5].

All the material parameters were measured in the Laboratory of Transport Processes at the Department of Materials Engineering and Chemistry, Faculty of Civil Engineering, Czech Technical University in Prague [6-10] and are summarized in Tables 1 and 2. Data for Mamut M2 mortar were measured by M. Jerman and have not been published yet. We used these symbols: $\rho$ - bulk density $\left[\mathrm{kg} / \mathrm{m}^{3}\right], \psi$ - porosity [\%], $c-$ specific heat capacity $[\mathrm{J} / \mathrm{kgK}], \mu-$ water vapour diffusion resistance factor [-], $w_{\text {hyg }}$ - hygroscopic moisture content by volume $\left[\mathrm{m}^{3} / \mathrm{m}^{3}\right], \lambda-$ thermal conductivity $[\mathrm{W} / \mathrm{mK}], \kappa_{a p p}-$ apparent moisture diffusivity $\left[\mathrm{m}^{2} / \mathrm{s}\right]$.

\subsection{Boundary conditions and time interval of simulation}

Initial and boundary conditions should be as realistic as possible. This was the reason why we used climatic data in the exterior in the form of Test Reference Year for Prague which contained average data for 30 years. On the interior side we used constant value of relative humidity $55 \%$ and temperature $21^{\circ} \mathrm{C}$ (see Fig. 1). The climatic data were obtained using Meteonorm software [11]. The 
284 Advanced Computational Methods and Experiments in Heat Transfer XII

Table 1: Material characteristics of thermal insulations.

\begin{tabular}{|l|c|c|c|}
\hline & $\begin{array}{c}\text { Expanded } \\
\text { polystyrene }\end{array}$ & $\begin{array}{c}\text { Rockwool } \\
\text { hydrophobic } \\
\text { mineral wool }\end{array}$ & $\begin{array}{c}\text { Rockwool } \\
\text { hydrophilic } \\
\text { mineral wool }\end{array}$ \\
\hline \hline$\rho\left[\mathrm{kg} / \mathrm{m}^{3}\right]$ & 50 & 270 & 90 \\
\hline$\psi[\%]$ & 98.4 & 88.0 & 96.7 \\
\hline$c[\mathrm{~J} / \mathrm{kgK}]$ & 1567 & 630 & 730 \\
\hline$\mu_{\text {dry cup }}[-]$ & 58 & 3.5 & 1.8 \\
\hline$\mu_{\text {wet cup }}[-]$ & 28.5 & 2.2 & 0.043 \\
\hline$\lambda_{\text {dry }}[\mathrm{W} / \mathrm{mK}]$ & 0.039 & 0.045 & 0.355 \\
\hline$\lambda_{\text {sat }}\left[\mathrm{W} / \mathrm{mK}^{2}\right]$ & 0.513 & 0.089 & $4.12 \mathrm{e}-7$ \\
\hline$\kappa_{\text {app }}\left[\mathrm{m}^{2} / \mathrm{s}\right]$ & $6.2 \mathrm{e}-12$ & $2.51 \mathrm{e}-10$ & 0.0004 \\
\hline$w_{\text {hyg }}\left[\mathrm{m}^{3} / \mathrm{m}^{3}\right]$ & 0.00018 & 0.007 & \\
\hline
\end{tabular}

Table 2: $\quad$ Material characteristics of other materials.

\begin{tabular}{|l|c|c|c|c|}
\hline & $\begin{array}{c}\text { Sandstone }- \\
\text { Božanov }\end{array}$ & Argillite & $\begin{array}{c}\text { Mamut M2 } \\
\text { mortar }\end{array}$ & $\begin{array}{c}\text { Lime- } \\
\text { pozzolana } \\
\text { render }\end{array}$ \\
\hline \hline$\rho\left[\mathrm{kg} / \mathrm{m}^{3}\right]$ & 2154 & 1353 & 1430 & 1690 \\
\hline$\psi[\%]$ & 16.1 & 39.0 & 42.6 & 34.1 \\
\hline$c[\mathrm{~J} / \mathrm{kgK}]$ & 675 & 1074 & 1020 & 877 \\
\hline$\mu_{\text {dry cup }}[-]$ & 13.38 & 5.66 & 12.4 & 29.03 \\
\hline$\mu_{\text {wet cup }[-]}$ & 5.54 & 4.1 & - & 11.57 \\
\hline$\lambda_{\text {dry }}[\mathrm{W} / \mathrm{mK}]$ & 3.42 & 0.428 & 0.481 & 0.886 \\
\hline$\lambda_{\text {sat }}\left[\mathrm{W} / \mathrm{mK}^{2}\right]$ & 6.235 & 0.968 & 2.022 & 2.19 \\
\hline$\kappa_{\text {app }}\left[\mathrm{m}^{2} / \mathrm{s}\right]$ & $2.50 \mathrm{e}-08$ & $5.29 \mathrm{e}-08$ & $1.07 \mathrm{e}-9$ & $2.01 \mathrm{e}-7$ \\
\hline$w_{\text {hyg }}\left[\mathrm{m}^{3} / \mathrm{m}^{3}\right]$ & 0.0074 & 0.128 & 0.0201 & 0.049 \\
\hline
\end{tabular}



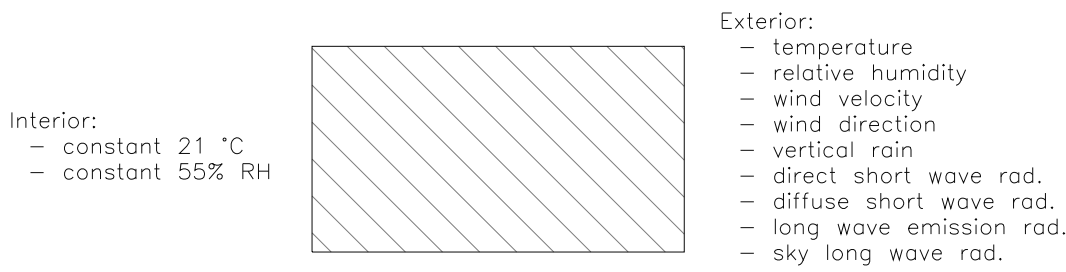

Figure 1: $\quad$ Boundary conditions.

simulation started on $1^{\text {st }}$ July and took 5 years. All the presented results are related to the last year of simulation, when the process reaches steady- state.

\section{Computational results}

All the computational results are summarized into several sets of figures. The first set shows distribution of relative humidity and temperature across the building envelope provided with different types of thermal insulation in summer or winter period. The subsequent figure shows distribution of temperature and moisture content in selected point of building envelope, which is advantageous from the point of view of freeze-thaw cycles evaluation. The figures clearly show influence of particular thermal insulating material on hygrothermal straining of whole building envelope. Because of similarity of several figures only the representative ones are chosen, rest of the results is summarized in Table 3.

Table 3: Number of freeze-thaw cycles under the exterior surface of the building envelope.

\begin{tabular}{|l|l|l|l|}
\hline & EPS & HFOB & HFIL \\
\hline Sandstone & 18 & 13 & 11 \\
\hline Argillite & 20 & 16 & 11 \\
\hline
\end{tabular}

\subsection{Sandstone masonry}

The proper choice of thermal insulating material for sandstone masonry is a difficult task. It requires sensitivity analysis, which results are presented in Figure 2. We can see there distribution of relative humidity across the envelope on $12^{\text {th }}$ of January, which is characteristic day of winter period according to the data of reference year. The differences between single insulation materials are significant. The best results are achieved when hydrophobic mineral wool is assumed, on the other hand the worst results gives the hydrophilic mineral wool. The difference in relative humidity reaches almost $30 \%$ on the material interface between adhesive layer and thermal insulation. 


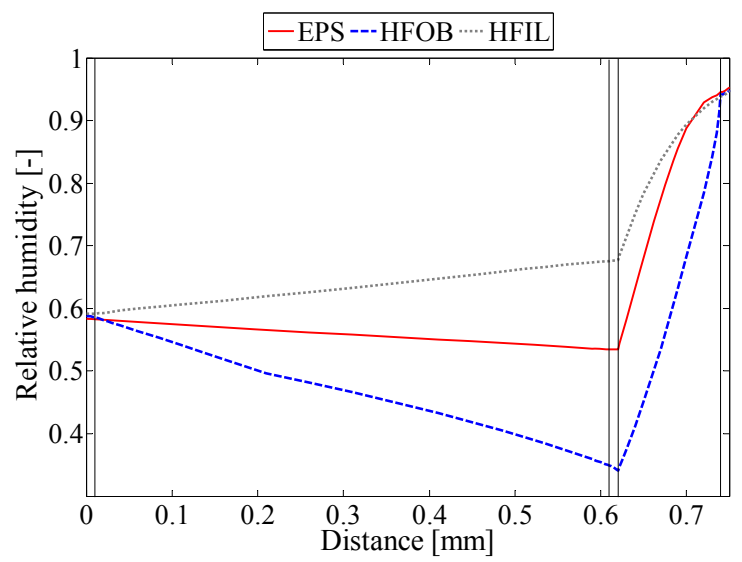

Figure 2: Distribution of relative humidity across the sandstone building envelope in $12^{\text {th }}$ January.

Figure 3 shows the distribution of temperature across the sandstone building envelope. From the point of view of thermal protection it is obvious; it does not matter which kind of investigated thermal insulation is chosen despite their different hygric properties.

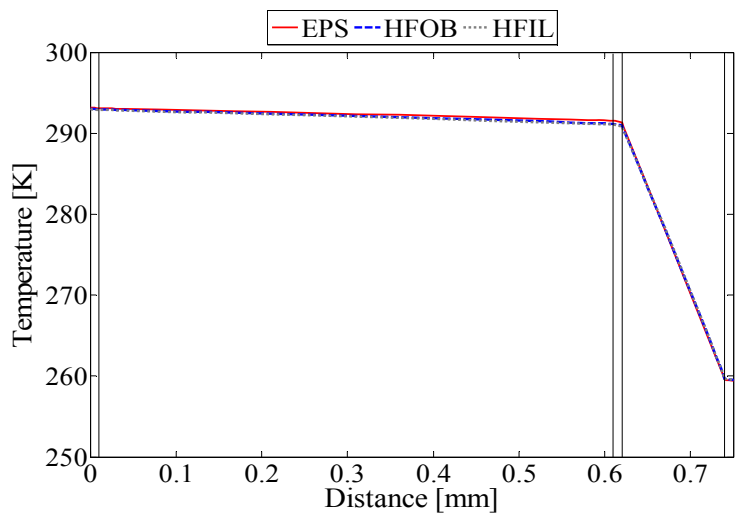

Figure 3: Distribution of temperature across the sandstone building envelope in $12^{\text {th }}$ January.

Analogous results were achieved in the summer, which is represented by $24^{\text {th }}$ August (see Figure 4). The worst results from the point of view of hygric performance are also achieved when hydrophilic mineral wool is considered. Contrary to winter period results, in the summer the best hygric behaviour shows a building envelope provided with EPS. 


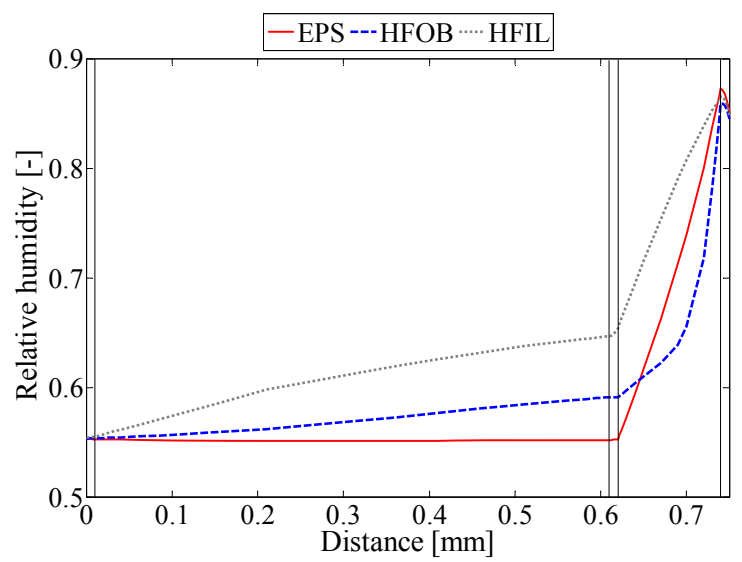

Figure 4: Distribution of relative humidity across the sandstone building envelope on $24^{\text {th }}$ August.

Also, in this case, the material of thermal insulation does not have a significant influence on the changes in thermal performance. This can be seen in Figure 5.

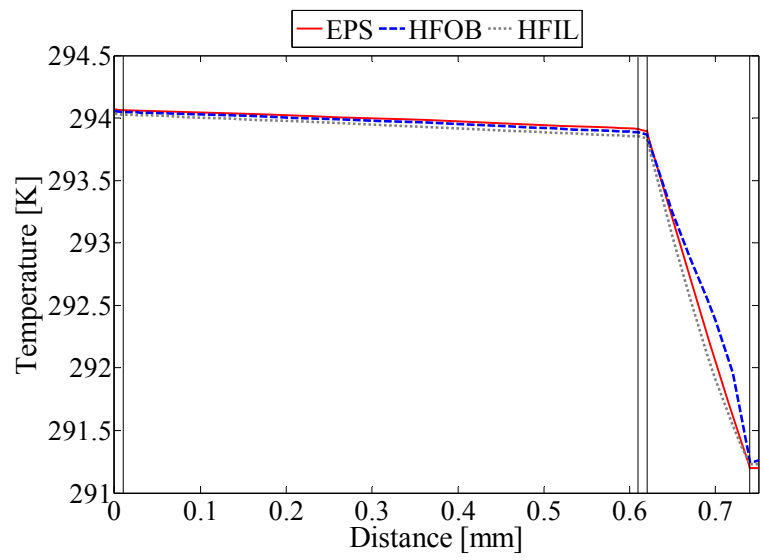

Figure 5: Distribution of temperature across the sandstone building envelope on $24^{\text {th }}$ August.

Figure 6 captures hygrothermal performance in $2 \mathrm{~mm}$ under the external surface of sandstone masonry provided with EPS. The grey colour shows the temperature and black colour the moisture content by volume. There are also two horizontal lines, the grey one shows a temperature of $0^{\circ} \mathrm{C}$, the black one shows hygroscopic moisture content by volume. If both these lines are crossed at the same time, propitious conditions for water freezing are created. This is the basic 
principle of freeze-thaw cycles evaluation. In this case, a large amount of freezing cycles will appear because of permanently low temperature in the winter months in combination with fluctuating moisture content which very often reaches the overhygroscopic moisture content.

The rest of the building envelopes has a very similar appearance so they are not presented using figures.

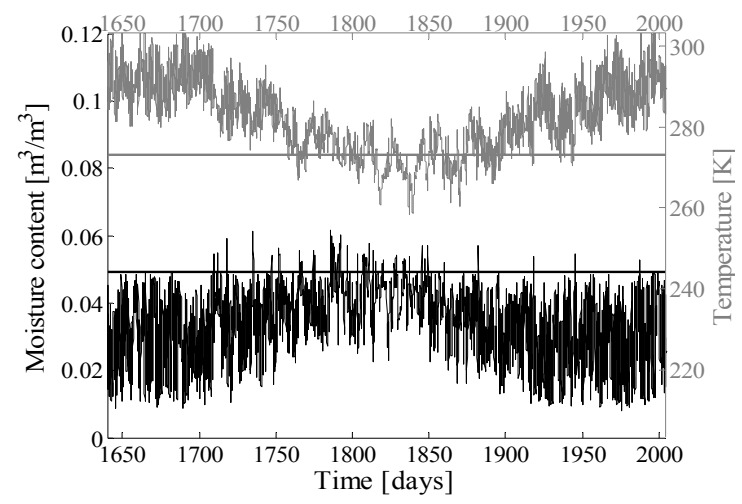

Figure 6: Hygrothermal performance of exterior plaster $2 \mathrm{~mm}$ under the surface, sandstone masonry provided by EPS.

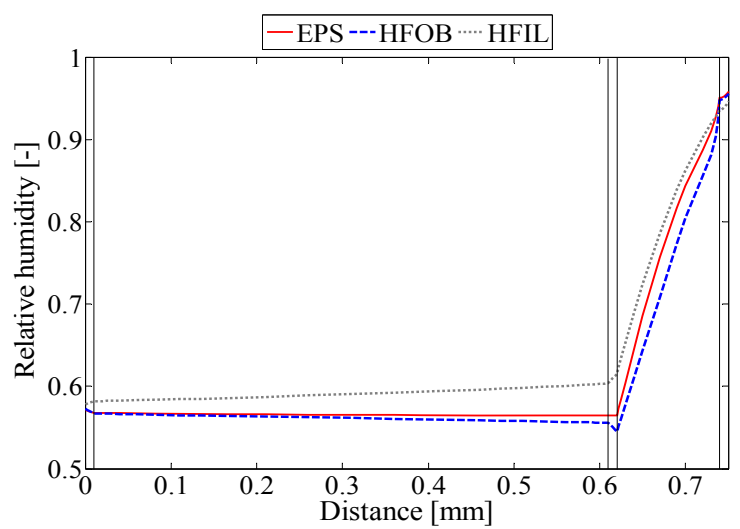

Figure 7: Distribution of relative humidity across the argillite building envelope on $12^{\text {th }}$ January.

\subsection{Argillite masonry}

Argillite masonry provided with different types of thermal insulation does not evidence such big differences in hygric performance as sandstone masonry presented above. This fact relatively simplifies the choice of insulating material. 
As we can see in Figures 7 and 9, the relative humidity profile in the winter and summer period is almost the same. In both cases the best results are achieved when hydrophobic mineral wool is applied. The same can be said about the temperature profiles shown in Figures 8 and 10.

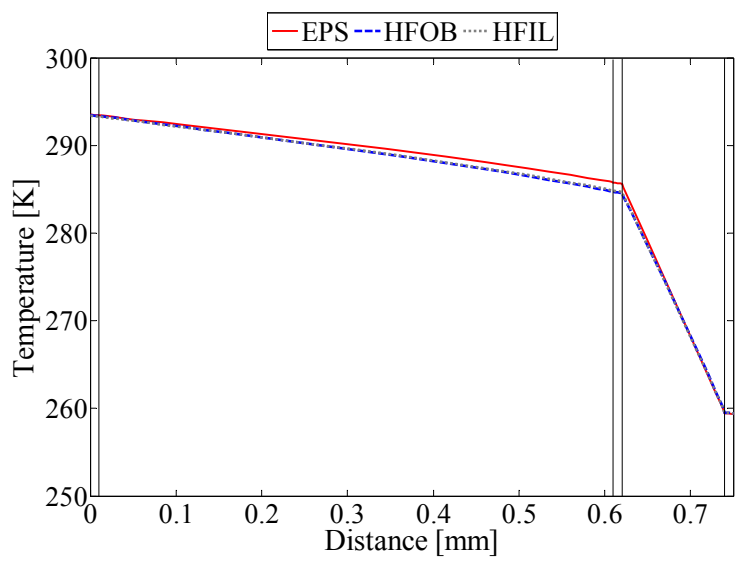

Figure 8: Distribution of temperature across the argillite building envelope on $12^{\text {th }}$ January.

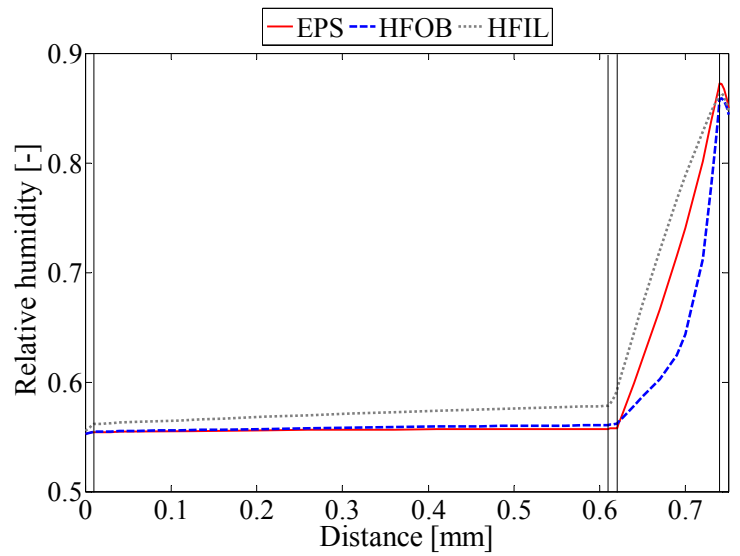

Figure 9: Distribution of relative humidity across the argillite building envelope on $24^{\text {th }}$ August. 


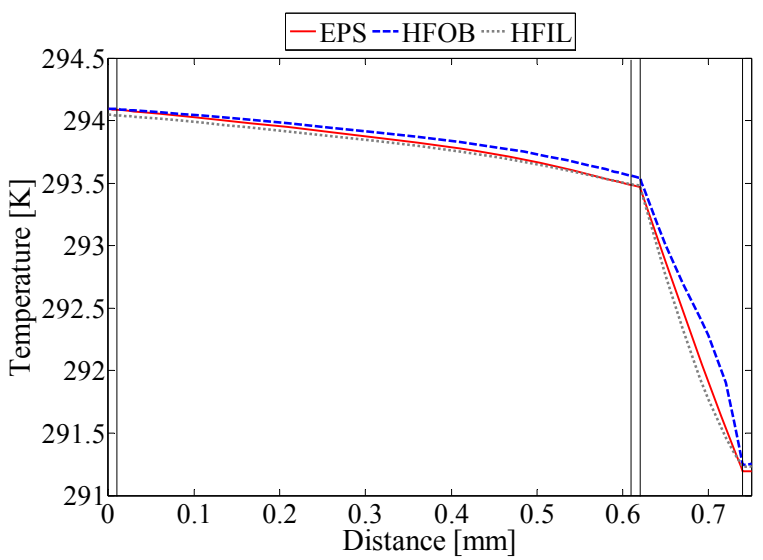

Figure 10: Distribution of temperature across the argillite building envelope in $24^{\text {th }}$ August.

\section{Discussion}

As the results of computational simulations show, to provide historical masonry with thermal insulation correctly is not as easy as it might appear. Even if the thermal insulation reliably protects the wall against climatic load, the hygric performance can get significantly worse. It is necessary to choose the thermal insulating material wisely with respect to hygric properties of material of a load bearing wall, which are in both cases not just fitting due to low moisture diffusivity.

Hydrophobic mineral wool seems to be the best choice for sandstone or argillite masonry. Thanks to hydrophobic agents, the insulation does not accept the liquid moisture as much as other investigated insulations and low water vapour diffusion resistance factor allows relatively quick transport of water vapour. The construction can then easily evaporate the moisture into the exterior.

Expanded polystyrene as a material of thermal insulation literally seals up the construction because besides low moisture diffusivity it also has a very high water vapour diffusion resistance factor. That means that the accepted moisture can hardly be released and only way is to evaporate into the interior.

In both cases, hydrophilic mineral wool rapidly increases the moisture of masonry. It has very high moisture diffusivity so it accepts liquid moisture very easily and transports it deeper into the construction. That explains the higher moisture level of masonry in all studied cases (see Figs. 2, 4, 7 and 9). Hydrophilic mineral wool can than appear as inapplicable, but there is still one big advantage of this insulation - it is very considerate to the applied external finishes. This can be explained by the high value of moisture diffusivity which decreases the moisture of external finish and thus protects it against liquid moisture freezing. We counted 11 freezing cycles appearing in external plaster during the reference year in sandstone and argillite masonry as well. 
The presence of expanded polystyrene had a very negative influence on the service life of applied external finishes, as well as hydrophobic mineral wool. As these materials do not accept the liquid moisture smoothly, the moisture accumulates in the plaster and its amount very easily reaches the overhygroscopic range. In combination with low temperatures, freeze-thaw cycles can arise with ease. A summary of all counted freeze-thaw cycles is presented in Table 3.

\section{Conclusions}

The analysis of historical building envelopes provided with exterior thermal insulation has been accomplished in this paper using a combined experimentalcomputational approach. According to the obtained results, a combination of historical masonry with expanded polystyrene is the worst possible choice. EPS not only increases the moisture of masonry but also exposes the external finish to abnormal climatic straining. Much better results were obtained when one of the mineral wools was used. Hydrophobic mineral wool gives better hygric performance of historical masonry, while hydrophilic mineral wool better protects applied external plaster. The choice of type of mineral wool depends then on the priorities of the owners or architectural heritage authorities.

\section{Acknowledgement}

This research has been supported by the Czech Science Foundation, under project No P105/12/G059.

\section{References}

[1] Černý, R., Complex System of Methods for Directed Design and Assessment of Functional Properties of Building Materials: Assessment and Synthesis of Analytical Data and Construction of the System. CTN CTU in Prague, pp. $192-201,2010$.

[2] Kočí, V., Kočí, J., Maděra, J. and Černý, R., Computer code HEMOT for hygrothermal assessment of thermal insulation systems. Thermophysics 2010. Brno: University of Technology, pp. 133-140, 2010.

[3] Kruis, J., Koudelka, T. and Krejčí, T., Efficient computer implementation of coupled hydro-thermo-mechanical analysis. Mathematics and Computers in Simulation, 80, pp. 1578-1588, 2010.

[4] Künzel, H. M., Simultaneous Heat and Moisture Transport in Building Components, PhD Thesis, IRB Verlag Stuttgart, 1995.

[5] Kočí, J., Kočí, V., Maděra, J., Rovnaníková, P. and Černý, R., Computational analysis of hygrothermal performance of renovation renders. Advanced Computational Methods and Experiments in Heat Transfer XI. Southampton: WIT Press, pp. 267-277, 2010. 
[6] Kočí, V., Jerman, M. and Černý, R., Hygric and Thermal Properties of Materials Involved in the Envelopes of Contemporary Buildings, Modern Methods and Advances in Structural Engineering and Construction, Singapore: Research Publishing Services, pp. 807-812, 2011.

[7] Jiřičková, M. and Černý, R., Effect of Hydrophilic Admixtures on Moisture and Heat Transport and Storage Parameters of Mineral Wool. Construction and Building Materials, 20, pp. 425-434, 2006.

[8] Vejmelková, E., Máca, P., Konvalinka, P. and Černý, R., Innovative Limepozzolana Renders for Reconstruction of Historical Buildings. Advanced Materials Research, 324, pp. 372-375, 2011.

[9] Pavlík, Z., Fiala, L., Pavlíková, M. and Černý, R., Water and Chloride Transport Properties of Renovation Plasters Developed for Historical Masonry. 12th International Conference on Durability of Building Materials and Components. Porto: Faculdade de Engenharia da Universidade do Porto, pp. 745-752, 2011.

[10] Pavlík, Z., Vejmelková, E., Pavlíková, M., Keppert, M. and Černý, R., Characterization of Building Stones Involved in Historical Masonry. Advanced Materials Research, 324, pp. 388-391, 2011.

[11] Meteonorm Version 6, software version 6.1.0.20 of April 2010, METEOTEST, Switzerland, 2010. 